Fang Li-Min, Huang Jian-Ping, Dai Jian-Cheng, Nie Xu-Liang*, Liu Chang-Xiang, Kang Nian-Qian and Huang Lin*

\title{
Crystal structure of methyl 4-acetoxybenzoate, $\mathrm{C}_{10} \mathrm{H}_{10} \mathrm{O}_{4}$
}

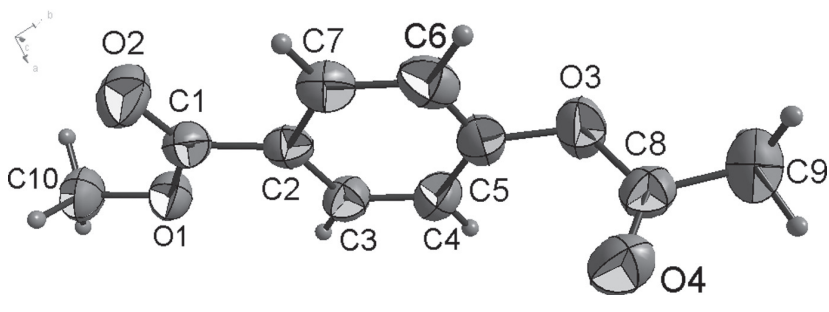

https://doi.org/10.1515/ncrs-2018-0591

Received December 19, 2018; accepted February 8, 2019; available online March 4, 2019

\begin{abstract}
$\mathrm{C}_{10} \mathrm{H}_{10} \mathrm{O}_{4}$, monoclinic, $C 2 / c$ (no. 15), $a=25.400(4) \AA$, $b=5.9738(10) \AA, \quad c=12.746(2) \AA, \quad \beta=94.318(2)^{\circ}$, $V=1928.5(6) \AA^{3}, Z=8, R_{\mathrm{gt}}(F)=0.0434, w R_{\mathrm{ref}}\left(F^{2}\right)=0.1276$, $T=296(2) \mathrm{K}$.
\end{abstract}

\section{CCDC no.: 1896096}

The asymmetric unit of the title crystal structure is shown in the figure. Tables 1 and 2 contain details on crystal structure and measurement conditions and a list of the atoms including atomic coordinates and displacement parameters.

\section{Source of material}

The mixture of methyl 4-hydroxybenzoate $(15.2 \mathrm{~g}, 0.1 \mathrm{~mol})$, acetic anhydride $(20.4 \mathrm{~g}, 0.2 \mathrm{~mol})$ and sulfuric acid $(1 \mathrm{~mL})$ was reacted at $80^{\circ} \mathrm{C}$ for $1 \mathrm{~h}$. After the reaction completed (monitored by TLC), colorless crystal was produced after cooled slowly. The product was filtered, and washed with

\footnotetext{
*Corresponding authors: Nie Xu-Liang, College of Sciences, Jiangxi Agricultural University, Nanchang 330045, P.R. China, e-mail: niexuliang1981@163.com; and Huang Lin, College of Bioscience and Bioengineering, Jiangxi Agricultural University, Nanchang 330045, P.R. China, e-mail: huanglin213@126.com Fang Li-Min and Dai Jian-Cheng: College of Bioscience and Bioengineering, Jiangxi Agricultural University, Nanchang 330045, P.R. China

Huang Jian-Ping: Institute of Functional Materials and Agricultural Applied Chemistry/Jiangxi Key Laboratory for Conservation and Utilization of Fungal Resources, Jiangxi Agricultural University, Nanchang 330045, P.R. China

Liu Chang-Xiang and Kang Nian-Qian: College of Sciences, Jiangxi Agricultural University, Nanchang 330045, P.R. China
}

Table 1: Data collection and handling.

\begin{tabular}{ll}
\hline Crystal: & Colourless block \\
Size: & $0.24 \times 0.18 \times 0.18 \mathrm{~mm}$ \\
Wavelength: & Mo $K \alpha$ radiation $(0.71073 \AA$ A $)$ \\
$\mu:$ & $0.10 \mathrm{~mm}^{-1}$ \\
Diffractometer, scan mode: & Bruker APEX-II, $\varphi$ and $\omega$ \\
$\theta_{\text {max }}$, completeness: & $25.5^{\circ},>99 \%$ \\
$N(h k l)_{\text {measured }}, N(h k l)_{\text {unique }}, R_{\text {int }}:$ & $4908,1787,0.023$ \\
Criterion for $I_{\text {obs }}, N(h k l)_{\text {gt }}:$ & $I_{\text {obs }}>2 \sigma\left(I_{\text {obs }}\right), 1496$ \\
$N(\text { param })_{\text {refined }}:$ & 130 \\
Programs: & Bruker [1], SHELX [2] \\
\hline
\end{tabular}

Table 2: Fractional atomic coordinates and isotropic or equivalent isotropic displacement parameters $\left(\AA^{2}\right)$.

\begin{tabular}{lrrrr}
\hline Atom & $\boldsymbol{x}$ & $\boldsymbol{y}$ & $\boldsymbol{Z}$ & $\boldsymbol{U}_{\text {iso }} / \boldsymbol{U}_{\text {eq }}$ \\
\hline C1 & $0.31186(6)$ & $0.1456(3)$ & $0.08294(12)$ & $0.0497(4)$ \\
C2 & $0.33954(6)$ & $0.3413(3)$ & $0.13256(11)$ & $0.0464(4)$ \\
C3 & $0.38768(6)$ & $0.4182(3)$ & $0.10100(13)$ & $0.0536(4)$ \\
H3 & 0.4042 & 0.3426 & 0.0488 & $0.064^{*}$ \\
C4 & $0.41086(7)$ & $0.6065(3)$ & $0.14710(14)$ & $0.0596(5)$ \\
H4 & 0.4430 & 0.6583 & 0.1265 & $0.072^{*}$ \\
C5 & $0.38564(7)$ & $0.7167(3)$ & $0.22430(13)$ & $0.0564(5)$ \\
C6 & $0.33877(7)$ & $0.6404(3)$ & $0.25816(13)$ & $0.0609(5)$ \\
H6 & 0.3228 & 0.7148 & 0.3114 & $0.073^{*}$ \\
C7 & $0.31583(7)$ & $0.4529(3)$ & $0.21235(13)$ & $0.0547(4)$ \\
H7 & 0.2841 & 0.4000 & 0.2349 & $0.066^{*}$ \\
C8 & $0.44297(7)$ & $0.9219(3)$ & $0.34400(13)$ & $0.0565(5)$ \\
C9 & $0.45889(10)$ & $1.1540(4)$ & $0.37491(18)$ & $0.0850(7)$ \\
H9A & 0.4384 & 1.2037 & 0.4308 & $0.128^{*}$ \\
H9B & 0.4528 & 1.2518 & 0.3155 & $0.128^{*}$ \\
H9C & 0.4957 & 1.1562 & 0.3984 & $0.128^{*}$ \\
C10 & $0.31264(8)$ & $-0.1320(3)$ & $-0.04792(16)$ & $0.0673(5)$ \\
H10A & 0.3092 & -0.2524 & 0.0010 & $0.101^{*}$ \\
H10B & 0.3337 & -0.1804 & -0.1031 & $0.101^{*}$ \\
H10C & 0.2783 & -0.0885 & -0.0776 & $0.101^{*}$ \\
O1 & $0.33776(4)$ & $0.05600(19)$ & $0.00601(9)$ & $0.0563(4)$ \\
O2 & $0.27017(5)$ & $0.0745(2)$ & $0.10763(12)$ & $0.0754(5)$ \\
O3 & $0.40570(6)$ & $0.9218(2)$ & $0.26309(10)$ & $0.0739(4)$ \\
O4 & $0.45881(6)$ & $0.7520(3)$ & $0.38437(12)$ & $0.0835(5)$ \\
\hline
\end{tabular}

water 3 times respectively. Then the crystals suitable for crystal structure analysis were obtained. Yield $90 \%$ (based on methyl 4-hydroxybenzoate). m.p. $83-85^{\circ} \mathrm{C}$ (m.p. $82-84{ }^{\circ} \mathrm{C}$ ). Elemental Anal. Calcd. (\%) for $\mathrm{C}_{10} \mathrm{H}_{10} \mathrm{O}_{4}(152.05)$ : C, 61.85; H, 5.19. Found (\%): C, 60.45; H, 5.33. 


\section{Experimental details}

All $\mathrm{H}$ atoms were included in calculated positions and refined as riding atoms, with $\mathrm{C}-\mathrm{H}=0.93 \AA$ with $U_{\text {iso }}(\mathrm{H})=1.5 U_{\text {eq }}(\mathrm{C})$ for methyl $\mathrm{H}$ atoms and $1.2 U_{\text {eq }}(\mathrm{C})$ for all other $\mathrm{H}$ atoms.

\section{Comment}

Pyromethyl, methyl hydroxybenzoate, as a preservative has good inhibition of mold, yeast, bacteria in $\mathrm{pH}$ 1-8 [3]. $p$-Hydroxybenzoate is able to destroy the cell membrane of microorganisms, inhibit the electron transfer and the activity of the respiratory enzyme of microbial cells [4-6]. Because of its strong activities and its applications, pyromethyl was widely used as preservatives in the pharmaceutical industry and food industry, cosmetics. The synthesis and application of $p$-hydroxybenzoate and its derivatives have attracted much attention [7-9]. We are still focused on the synthesis and antibacterial activities of preservatives. In order to synthesis novel preservatives, we have designed and synthesized a series of flavonoids carboxylate glycosides.

There is one crystallographic independant molecule in the asymmtric unit. The molecule is in a general position, giving eight molecules in each unit cell. In the molecule of the title compound bond lengths and angles are very similar to those given in the literature for methyl $p$-hydroxybenzoate [10,11]. In the title structure, the part of methyl $p$-hydroxybenzoate is approximately planar. The dihedral angle formed by the $\mathrm{C} 2-\mathrm{C} 7$ plane with the carboxlate group $\mathrm{C1}-\mathrm{O} 1-\mathrm{O} 2$ plane is $3.2(1)^{\circ}$. The acetyl group is perpendicular to methyl $p$-hydroxybenzoate and the dihedral angle is $85.6(1)^{\circ}$.

Acknowledgements: X-ray data were collected at Instrumental Analysis Center Nanchang Hangkong University, Nanchang, 330063, People's Republic of China. This work was supported by the Reform of Higher Education Foundation of Jiangxi Province (No. JXJG-17-3-18), the Natural Science Foundation of Science and Technology Department of Jiangxi
Province (Nos. 20171BBE50027, 20171BBG70029), Natural Science Foundation of Education Department of Jiangxi Province (Nos. GJJ160382, GJJ170274, GJJ170278), and Natural Science Foundation of Nanchang City (No. 2018CXTD014).

\section{References}

1. Bruker. APEX2, SAINT and SADABS. Bruker AXS Inc., Madison, WI, USA (2009).

2. Sheldrick, G. M.: A short history of SHELX. Acta Crystallogr. A64 (2008) 112-122.

3. Zhang, L. P.; Wang, W. J.; Li, Z.; Xu, C. Y.; Jiang, A. J.; Peng, X.: Preliminary study on degradation bacteria of methyl hydroxybenzoate. Chin. J. Jiangsu Agric. Sci. 46 (2018) 337-340.

4. Xu, Y. Y.; Ye, S. M.; Zhao, Y. H.; Cheng, F.; Huang, X. H.; Yang, M.: Preparation and component analysis of biodiesel catalyzed by functionalized dication ionic liquid. Acta Agric. Univ. Jiangxiensis 38 (2016) 27-33.

5. Huang, Y.; Zhao, K. X.; Shen, X. H.: Genetic and biochemical characterization of a 4-hydroxybenzoate hydroxylase from Corynebacterium glutamicum. Appl. Microbiol. Biotechnol. 78 (2008) 75-83.

6. Valkova, N.; Lépine, F.; Labrie, L.: Purification and characterization of PrbA, a new esterase from Enterobacter cloacae hydrolyzing the esters of 4-hydroxybenzoic acid (parabens). J. Biol. Chem. 278 (2003) 12779-12785.

7. Liu, Y. T.; Fu, Q.; Liang, G. T.; Yin, D. W.: Optimization of synthesis conditions of novel process methylparaben by response surface methodology. Chin. J. Food additives 1 (2014) 158-162.

8. Ma, Y. L.; Zhou, R. J.; Zeng, X. Y.; Qiu, S. S.; Nie, L. J.: Synthesis and antimicrobial activity of novel cis/trans-but-2-enedioic acid esters containing a hydroxybenzoic acid methyl ester moiety. Chin. J. Food Science 35 (2014) 118-122.

9. Lin, X. T.: Studies on the crystal structure of $p$-substituted benzoates. Chin. J. Struct. Chem. 2 (1983) 213-218.

10. Gelbrich, T.; Braun, D. E.; Ellern, A.; Griesser, U. J.: Four polymorphs of methyl paraben: structural relationships and relative energy differences. Cryst. Growth Des. 13 (2013) 1206-1217.

11. Fun, H. K.; Jebas, S. R.: A second monoclinic polymorph of methyl 4-hydroxybenzoate. Acta Crystallogr. E64 (2008) 01255. 